\title{
Calcium supplementation prevents obesity, hyperleptinaemia and hyperglycaemia in adult rats programmed by early weaning
}

\author{
Jessica Lopes Nobre, Patricia Cristina Lisboa, Natália da Silva Lima, Juliana Gastão Franco, \\ José Firmino Nogueira Neto, Egberto Gaspar de Moura and Elaine de Oliveira* \\ Department of Physiological Sciences, Roberto Alcantara Gomes Biology Institute, State University of Rio de Janeiro, $5^{\circ}$ andar, \\ Avenue 28 de Setembro, 87, Rio de Janeiro, RJ 20551-030, Brazil
}

(Submitted 14 December 2010 - Final revision received 25 May 2011 - Accepted 20 June 2011 - First published online 9 November 2011)

\section{Abstract}

It is known that Ca therapy may have anti-obesity effects. Since early weaning leads to obesity, hyperleptinaemia and insulin resistance, we studied the effect of dietary Ca supplementation in a rat model. Lactating rats were separated into two groups: early weaning (EW) - dams were wrapped with a bandage to interrupt lactation in the last $3 \mathrm{~d}$ of lactation and control (C) - dams whose pups had free access to milk during the entire lactation period $(21 \mathrm{~d})$. At $120 \mathrm{~d}$, EW and C offspring were subdivided into four groups: (1) C, received standard diet; (2) $\mathrm{CCa}$, received $\mathrm{Ca}$ supplementation ( $10 \mathrm{~g}$ of calcium carbonate $/ \mathrm{kg}$ of rat chow); (3) EW, received standard diet; (4) EWCa, received Ca supplementation similar to CCa. The rats were killed at $180 \mathrm{~d}$. The significance level was at $P<0 \cdot 05$. Adult EW offspring displayed hyperphagia (28\%), higher body weight (9\%) and adiposity (77\%), hyperleptinaemia (twofold increase), hypertriacylglycerolaemia (64\%), hyperglycaemia (16\%), higher insulin resistance index (38\%) and higher serum 25-hydroxyvitamin $\mathrm{D}_{3}$ (fourfold increase), but lower adiponectinaemia:adipose tissue ratio (44\%). In addition, they showed Janus tyrosine kinase 2 and phosphorylated signal transducer and activator of transcription 3 underexpression in hypothalamus (36 and 34\%, respectively), suggesting leptin resistance. Supplementation of $\mathrm{Ca}$ for 2 months normalised these disorders. The EW group had no change in serum insulin, thyroxine or triiodothyronine, and $\mathrm{Ca}$ treatment did not alter these hormones. In conclusion, we reinforced that early weaning leads to late development of some components of the metabolic syndrome and leptin resistance. Dietary Ca supplementation seems to protect against the development of endocrine and metabolic disorders in EW offspring, maybe through vitamin D inhibition.

Key words: Early weaning: Obesity: Hormonal resistance: Calcium therapy

Obesity is an important public health problem ${ }^{(1)}$. In $2008,1 \cdot 5$ billion adults, 20 years and older, were overweight. Of these, over 200 million men and nearly 300 million women were obese. It is important to emphasise that $65 \%$ of the world's population live in countries where overweight and obesity kill more people than underweight ${ }^{(2)}$.

Some studies have shown benefits of breast-feeding in reducing and preventing obesity ${ }^{(3,4)}$. The protective effect of breast-feeding against obesity is proportional to the duration and exclusivity of breast-feeding ${ }^{(3,5)}$. Exclusive breast-feeding is defined by the WHO as the consumption of breast milk until 6 months without any other type of food intake, juice or even water ${ }^{(6)}$. However, $<35 \%$ of children worldwide are exclusively breast-fed during the first postnatal 4 months ${ }^{(7)}$. Weaning is defined as the introduction of any food in the diet of a child who had a regimen of exclusive breast-feeding ${ }^{(8)}$. Thus, early weaning would be the cessation of natural breast-feeding before the child is 6 months old ${ }^{(9)}$.

It is well known that an adequate nutrient supply during early life is essential to establish the future endocrine and metabolic status. In fact, epidemiological and experimental data suggest that intra-uterine undernutrition is closely associated with adulthood obesity related to detrimental metabolic functions ${ }^{(10,11)}$, giving rise to the concept of 'developmental origins of health and disease'. This association has been denominated programming, which is defined as a biological phenomenon that determines the relationship between physical and chemical stimuli in critical periods of early life (gestation and lactation) with the future functional status $^{(12)}$. In addition, malnutrition only during lactation can programme for metabolic and endocrine disorders of the progeny in adulthood ${ }^{(13-17)}$. In two different models of

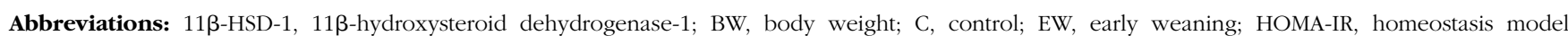
assessment of insulin resistance; JAK2, Janus tyrosine kinase 2; pJAK2, phosphorylated Janus tyrosine kinase 2; pSTAT3, phosphorylated signal transducer and activator of transcription 3; SOCS3, suppressor of cytokine signalling 3; VFM, visceral fat mass.

*Corresponding author: Dr E. d. Oliveira, fax +5521 28688029, email elainedeoliveir@pq.cnpq.br 
precocious weaning, our group evidenced the programming for metabolic syndrome parameters, such as obesity, type 2 diabetes and dyslipidaemia. In the first model, the suppression of lactation through maternal treatment with bromocriptine (a prolactin inhibitor) for $3 \mathrm{~d}$ caused milk yield inhibition and programmed the offspring for higher total and central fat, hyperleptinaemia, resistance to the anorexigenic action of leptin ${ }^{(18)}$, insulin resistance, lower HDL-cholesterol, higher serum TAG and cholesterol concentrations in adulthood ${ }^{(19)}$ as well as hypothyroidism ${ }^{(20)}$. Recently, in the second model of early weaning caused by lactation interruption with breast banding, the adult progeny showed higher adiposity, higher TAG and insulin resistance ${ }^{(21)}$. In addition, these animals also displayed lower hypothalamic Janus tyrosine kinase 2 (JAK2), phosphorylated signal transducer and activator of transcription 3 (pSTAT3) and higher suppressor of cytokine signalling 3 (SOCS3) levels, a feature that indicates leptin resistance. This second programming model is advantageous since lactation interruption occurs without the use of pharmacological substances or maternal separation.

The correction of metabolic disturbance observed in obesity is important for reducing cardiometabolic risk. Nutritional bioactive compounds have been used in the prevention of chronic diseases associated with obesity, acting as an adjunct of weight loss, because they are able to elevate energy expenditure and promote satiety ${ }^{(22)}$. Several studies have investigated the relationship of dietary Ca with energy balance management. Some studies have shown that a diet rich in $\mathrm{Ca}$ reduced body weight $(\mathrm{BW})^{(23)}$ and adiposity ${ }^{(24-26)}$, and improved both insulin sensitivity ${ }^{(27-29)}$ and lipid profile ${ }^{(30,31)}$.

One hypothesis for the explanation of the beneficial effect of Ca supplementation is its ability to modulate energy metabolism through calciotropic hormone concentrations: calcitriol and parathyroid hormone ${ }^{(32)}$, which seem to be the main mechanism for the anti-obesity effect of Ca supplementation. Calcitriol rapidly increases $\mathrm{Ca}$ uptake by the adipocyte, decreasing uncoupling protein activity, lipolysis and apoptosis. Higher $\mathrm{Ca}$ intake, decreasing parathyroid hormone and calcitriol levels, induce opposite effects in adipocytes. A diet poor in Ca increasing these hormones leads to lipogenesis, and inhibits lipolysis and lipid oxidation. Thus, a Ca-rich diet could cause opposite effects, decreasing lipid storage $^{(32,33)}$. Another hypothesis is that $\mathrm{Ca}$ has the ability to form insoluble complexes with lipids (soaps) in the intestine, increasing faecal excretion and decreasing their absorption, which reduces the available energy to the body, contributing to its anti-obesity effect ${ }^{(34,35)}$. There is strong evidence that Ca has a specific action on appetite control in rats ${ }^{(36)}$ and overweight women ${ }^{(37)}$. Moreover, recently Gilbert et al. ${ }^{(38)}$ have shown that milk supplementation attenuates the known increased motivation to eat, which occurs during BW loss.

Thus, considering that dietary Ca therapy could have an anti-obesity action, in the present study, we evaluated the possible beneficial effects of Ca supplementation in preventing some endocrine-metabolic alterations, as higher adiposity, dyslipidaemia, peripheral insulin resistance and central leptin resistance, which have been previously found in the experimental model of obesity programmed by the interruption of lactation in the last $3 \mathrm{~d}^{(21)}$.

\section{Materials and methods}

The use of the animals according to our experimental design was approved by the Animal Care and Use Committee of the Biology Institute of the State University of Rio de Janeiro (CEA/017/2009), which based its analysis on the principles adapted and promulgated by Brazilian Law no. 11.794/2008. Wistar rats were kept in a room with controlled temperature $\left(25 \pm 1^{\circ} \mathrm{C}\right)$ and artificial light-dark cycles (lights on 07.00 hours, lights off 19.00 hours). Virgin female rats, 3 months old, were caged with male rats (3:1), and after mating, each female was placed in an individual cage with free access to food and water until delivery. We only used dams whose litter size was ten pups in order to avoid the influence of the litter size in the programming effect. At birth, to maximise the lactation performance ${ }^{(39)}$, the litters were adjusted to six male pups per dam.

\section{Experimental model of programming by early weaning}

After birth, twenty lactating rats were randomly divided into two groups:

(1) Early weaning (EW, $n$ 10) - dams were lightly anaesthetised with thiopental $(0.06 \mathrm{mg} / \mathrm{ml}$ per $100 \mathrm{~g})$ and wrapped with a bandage to interrupt lactation in the last $3 \mathrm{~d}$ of lactation.

(2) Control (C, $n$ 10) - dams whose pups had a standard lactation period, i.e. weaning at $21 \mathrm{~d}$ of lactation.

EW and C groups received food directly into the cage and pups had easy access to drinking-water. From postnatal day 21 until postnatal day 180, BW and food intake (g) of offspring were monitored every $4 \mathrm{~d}$, and feed efficiency was calculated (BW gain/g food intake). We used two offspring from each dam, which were randomly chosen to be followed throughout the experiments, one of them to be treated with Ca.

\section{Dietary calcium supplementation for 2 months}

At $120 \mathrm{~d}$, EW and $\mathrm{C}$ offspring were subdivided into four groups (n 10/group): (1) C, received standard rat chow; (2) control Ca (CCa), received standard chow supplemented with calcium carbonate; (3) EW, received standard rat chow; (4) early weaning $\mathrm{Ca}(\mathrm{EWCa})$, received standard rat chow supplemented with calcium carbonate.

Calcium carbonate was added in the standard chow. The Ca-enriched diet provided twice the amount of $\mathrm{Ca}$ (in the form of calcium carbonate) that is recommended for rodents, which is $5 \mathrm{~g} \mathrm{Ca} / \mathrm{kg}$ of chow ${ }^{(40)}$. This amount is based on the recommendation of supplementation for human subjects, where values of up to two times the recommended amount have no toxic effect. Ca was supplemented from postnatal day 120 until postnatal day 180, at which time all rats were killed by quick decapitation, with no prior anaesthesia since 
it affects hormone and lipid metabolism ${ }^{(41)}$. Blood, hypothalamus, liver, carcass and visceral fat mass (VFM) were excised and kept frozen $\left(-80^{\circ} \mathrm{C}\right)$. Calcaemia and phosphataemia were measured using colourimetric BioSystems commercial kits (BioSystems, Barcelona, Spain). The metabolite 25-hydroxyvitamin $\mathrm{D}_{3}$ was measured using monoclonal antibody immunoassay (Elecsys and Cobas immunoassay analysers; Roche Diagnostics GmbH, Mannheim, Germany), with a range of detection from 4.0 to $100 \mathrm{ng} / \mathrm{ml}$. This hormone is generally measured to determine the overall vitamin $\mathrm{D}$ status.

\section{Body composition evaluation}

After killing, VFM was quickly excised and weighed for evaluation of the central adiposity - mesenteric, epididymal and retroperitoneal ${ }^{(15)}$, and data were expressed as $\mathrm{g} / 100 \mathrm{~g}$ BW. Total fat was determined by carcass analysis ${ }^{(17)}$. All rats were eviscerated; carcasses were weighed, autoclaved for $1 \mathrm{~h}$ and homogenised in distilled water (1:1). Homogenates were stored at $4^{\circ} \mathrm{C}$ for analysis. Homogenates $(3 \mathrm{~g})$ were used to determine the fat content gravimetrically. Samples were hydrolysed in a shaking water-bath at $70^{\circ} \mathrm{C}$ for $2 \mathrm{~h}$ with $30 \% \mathrm{KOH}$ and ethanol. Total fatty acids and non-esterified cholesterol were removed with three successive washings with petroleum diethyl ether. After drying overnight in vacuum, all tubes were weighed and data were expressed as $\mathrm{g}$ fat $/ 100 \mathrm{~g}$ carcass. The estimate of the subcutaneous fat was calculated by subtracting the visceral fat from the total fat. Data were expressed as $g$ of fat/100 g carcass.

\section{Serum hormones measurement by RIA}

Blood samples were centrifuged $\left(1500 \mathrm{~g} / 20 \mathrm{~min}\right.$ per $\left.4^{\circ} \mathrm{C}\right)$ to obtain serum, which was kept at $-20^{\circ} \mathrm{C}$ until assay. All determinations were performed in one assay and samples were analysed in duplicate. Leptin was measured with a specific RIA kit (Linco Research, St Charles, MO, USA) with a range of detection from 0.5 to $50 \mathrm{ng} / \mathrm{ml}$; the intra-assay variation was $2 \cdot 9 \%$. Insulin was determined using a RIA kit (ICN Pharmaceuticals, Inc., Orangeburg, NY, USA) with an assay sensitivity of $0.1 \mathrm{ng} / \mathrm{ml}$; the intra-assay variation was $4 \cdot 1 \%$. Adiponectin was measured with a specific RIA kit (Linco Research) with an assay sensitivity of $0.5 \mathrm{ng} / \mathrm{ml}$; the intra-assay variation was $7 \cdot 1 \%$. Free and total thyroid hormone levels were determined with a commercial RIA kit (ICN Pharmaceuticals, Inc.) with assay sensitivities of $0.45 \mathrm{ng} / \mathrm{l}$ (free thyroxine), $0.06 \mathrm{pg} / \mathrm{ml}$ (total triiodothyronine), $7.6 \mu \mathrm{g} / \mathrm{l}$ (total thyroxine), $0.06 \mathrm{pg} / \mathrm{ml}$ (free triiodothyronine). The intra-assay variations were $2.8 \%$ (free thyroxine) and $3.6 \%$ (total triiodothyronine), $3 \cdot 8 \%$ (total thyroxine) and $4 \%$ (free triiodothyronine).

\section{Glucose homeostasis evaluation}

Fasting blood glucose was determined from the tail vein of fasting rats using a glucometer (ACCU-CHEK Advantage; Roche Diagnostics, Mannhein, Germany). Insulin sensitivity was assessed by

$$
\begin{aligned}
\text { HOMA-IR }= & (\text { insulin }(\mu \mathrm{U} / \mathrm{ml}) \\
& \times \operatorname{serum} \text { glucose }(\mathrm{mmol} / \mathrm{l})) / 22 \cdot 5,
\end{aligned}
$$

where HOMA-IR is homeostasis model assessment of insulin resistance.

As hypertrophic adipocytes release less adiponectin, both adiponectinaemia:total fat ratio and adiponectinaemia:VFM ratio were used to evaluate insulin resistance ${ }^{(42)}$.

\section{Lipid profile determination}

Serum total cholesterol, TAG and HDL were analysed using Biosystem commercial test kits. LDL-cholesterol and VLDLcholesterol were obtained using Friedewald calculations:

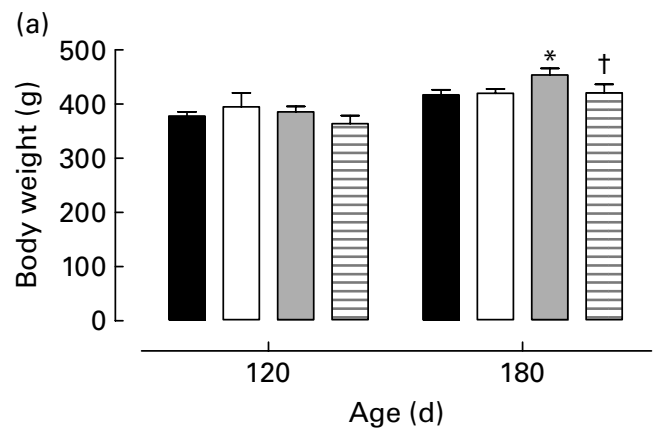

(b)
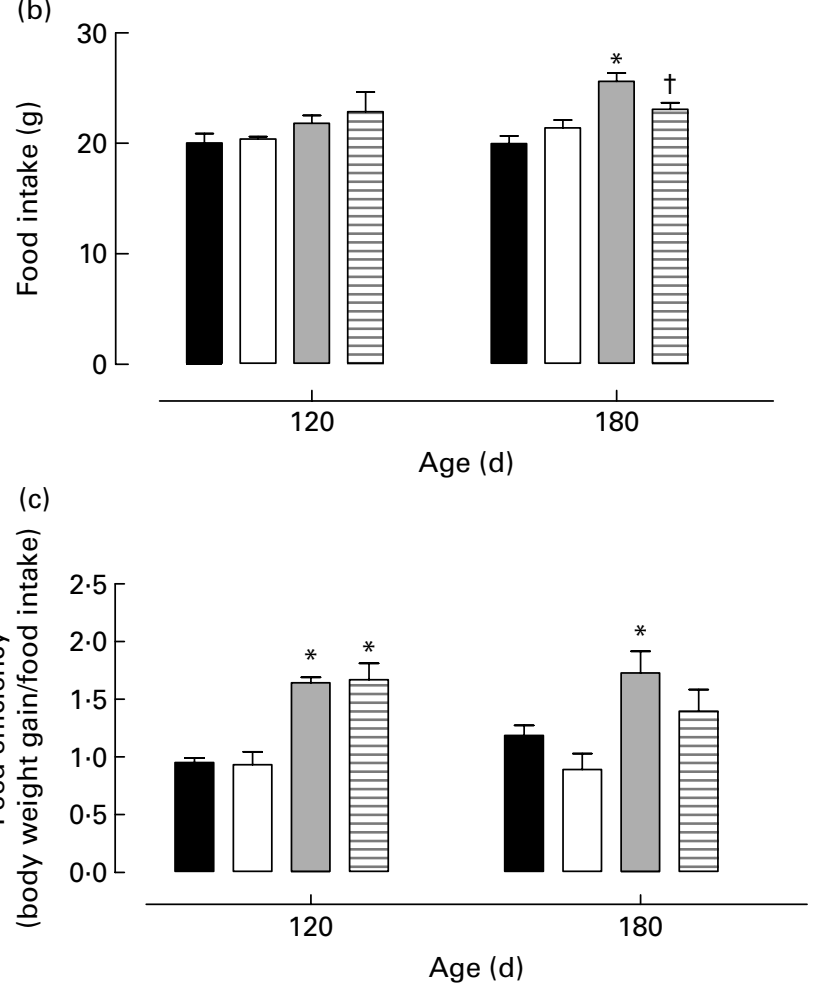

Fig. 1. (a) Body weight, (b) food intake and (c) feed efficiency at $120 \mathrm{~d}$ (first day of calcium (Ca) supplementation) and $180 \mathrm{~d}$ (kill) of control (C, $\mathbf{C})$ and early weaning (EW, $\square$ ) offspring treated with dietary Ca supplementation for 2 months ( $\mathrm{CCa}(\square)$ and EWCa $(\mathrm{G}))$. Values are means, with their standard errors represented by vertical bars, $n$ 10. * Mean values were significantly different from those of $C(P<0.05)$. † Mean values were significantly different from those of EW $(P<0.05)$. 

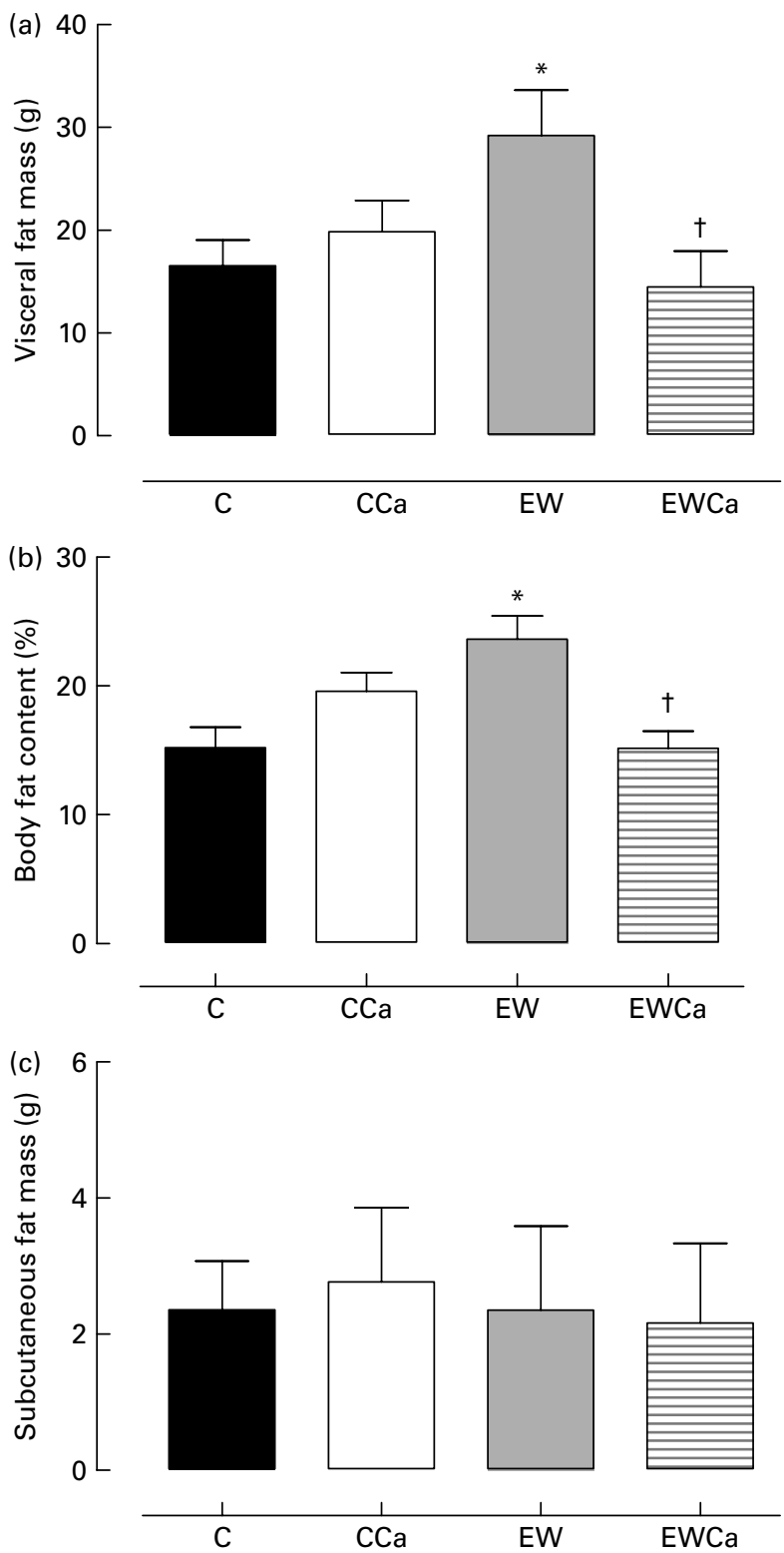

Fig. 2. (a) Visceral fat, (b) body total fat and (c) subcutaneous fat masses of adult control (C) and early weaning (EW) offspring treated with dietary calcium $(\mathrm{Ca})$ supplementation for 2 months $(\mathrm{CCa}$ and $\mathrm{EWCa})$. Values are means, with their standard errors represented by vertical bars, $n 10$. * Mean values were significantly different from those of $C(P<0.05)$. † Mean values were significantly different from those of $\mathrm{EW}(P<0.05)$.

(1) LDL-cholesterol $(\mathrm{mg} / \mathrm{l})=($ total cholesterol $-\mathrm{HDL}-$ cholesterol - TAG) $/ 5$.

(2) VLDL-cholesterol $(\mathrm{mg} / \mathrm{l})=\mathrm{TAG} / 5$.

\section{Western blot analysis}

To obtain cell extracts, the hypothalamus was homogenised in ice-cold lysis buffer (50 mm-HEPES, $1 \mathrm{~mm}-\mathrm{MgCl}_{2}$, $10 \mathrm{mm-EDTA}$, Triton X-100 1\%, pH 6.4) containing the following protease inhibitors: $10 \mu \mathrm{g} / \mu \mathrm{l}$ aprotinin, $10 \mu \mathrm{g} / \mu \mathrm{l}$ leupeptin, $2 \mu \mathrm{g} / \mu \mathrm{l}$ pepstatin and $1 \mathrm{~mm}$-phenylmethylsulfonyl fluoride (SigmaAldrich, St Louis, MO, USA). After centrifugation (7500 $\boldsymbol{g}$ for
$5 \mathrm{~min}$ ), homogenates were stored at $-20^{\circ} \mathrm{C}$. OB-R (leptin receptor), JAK2, pJAK2, pSTAT3 and SOCS3 contents were analysed by Western blot using actin as an internal control.

Briefly, protein concentrations were determined by the BCA Protein Assay Kit (Thermo Scientific, Rockford, IL, USA). Samples (30 $\mu$ g total protein) were separated by $10 \%$ SDS-PAGE according to the molecular weight of each protein and transferred onto nitrocellulose membranes (Hybond ECL; Amersham Pharmacia Biotech, Little Chalfont, Bucks, UK). Rainbow standard markers (Amersham Biosciences, Uppsala, Sweden) were run in parallel to estimate the molecular weights. Membranes were blocked with 5\% non-fat milk in
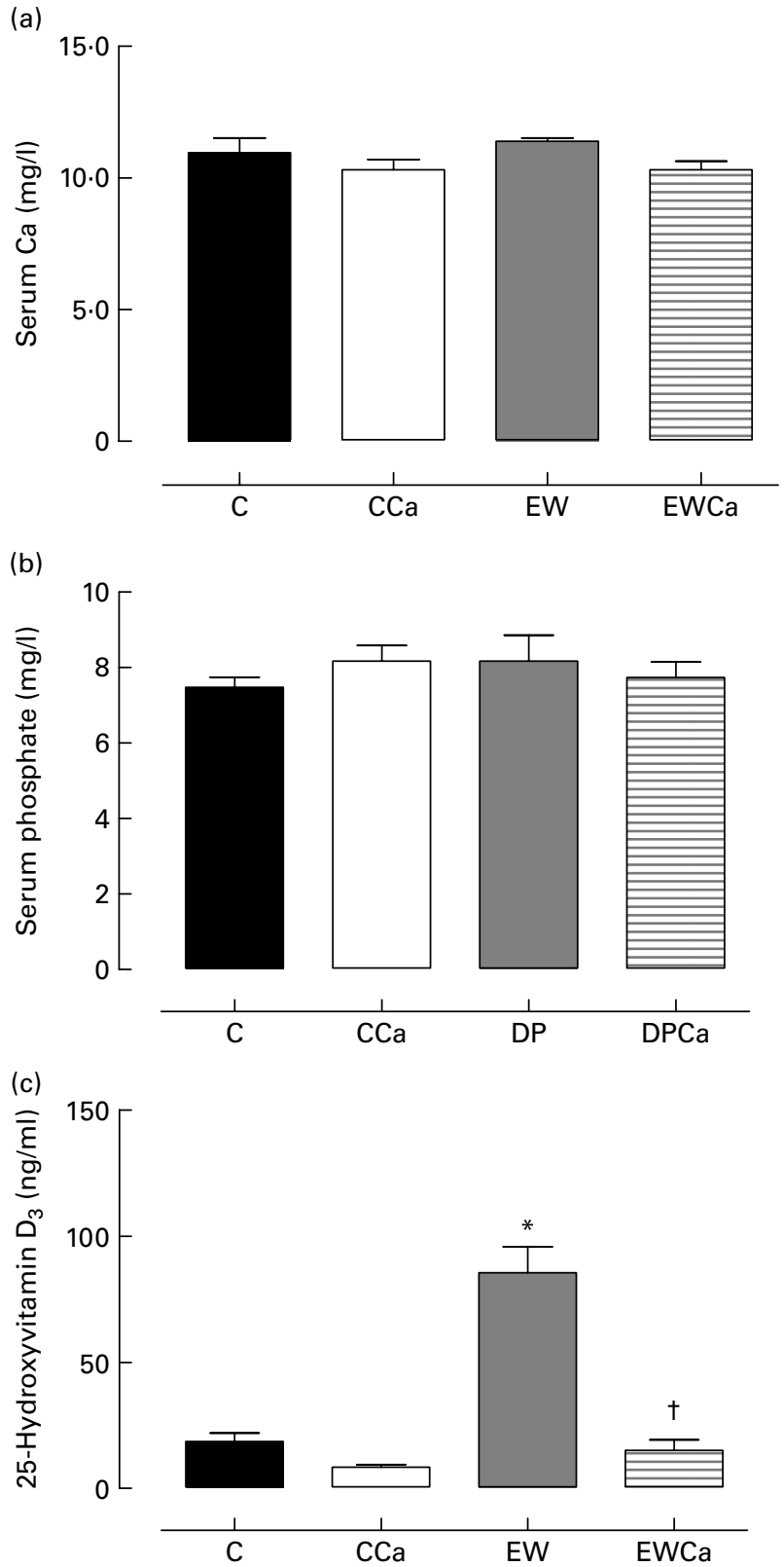

Fig. 3. (a) Serum calcium (Ca), (b) serum phosphate and (c) 25-hydroxyvitamin $\mathrm{D}_{3}$ of adult control (C), CCa, early weaning (EW) and EWCa rats. Values are means, with their standard errors represented by vertical bars, $n$ 10. ${ }^{*}$ Mean values were significantly different from those of $C(P<0.05)$. † Mean values were significantly different from those of EW $(P<0.05)$. 
Tween-Tris-buffered saline (20 mm-Tris-HCl, pH 7·5, 500 mm$\mathrm{NaCl}, 0 \cdot 1 \%$ Tween-20) for $1 \mathrm{~h}$. Specific primary antibodies (Santa Cruz Biotechnology, Inc., Santa Cruz, CA, USA) used were anti-OB-R, anti-JAK2, anti-pJAK2, anti-pSTAT3, anti-SOCS3 and anti-actin. Membranes were incubated with primary antibodies at a 1:500 dilution in Tween-Tris-buffered saline for $1 \mathrm{~h}$, with the appropriate secondary antibody (1:10000; peroxidase-conjugated IgG; Santa Cruz Biotechnology, Inc.) for $1 \mathrm{~h}$ and then with streptavidin (1:10 000; Zymed, San Francisco, CA, USA) for $1 \mathrm{~h}$. Targeted proteins were detected by enhanced chemiluminescence (Amersham
Pharmacia Biotech, Piscataway, NJ, USA) and then exposed to X-ray film for $10 \mathrm{~s}$ to $30 \mathrm{~min}$. Images were scanned and bands were quantified by densitometry using Image $\mathrm{J} 1.34 \mathrm{~s}$ software (Wayne Rasband National Institute of Health, Bethesda, MA, USA).

\section{Statistical analysis}

Results are reported as means with their standard errors. GraphPad Prism 5 (GraphPad Software, Inc., La Jolla, CA, USA) was used for statistical analyses and graphics.

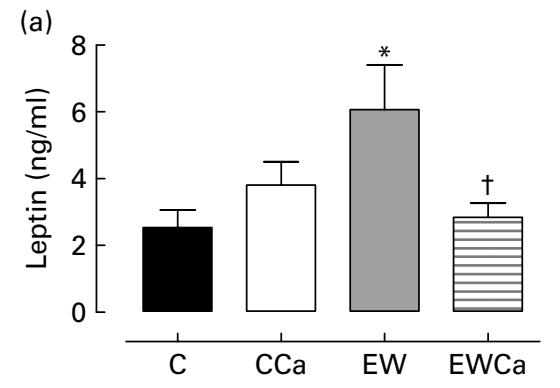

(b)

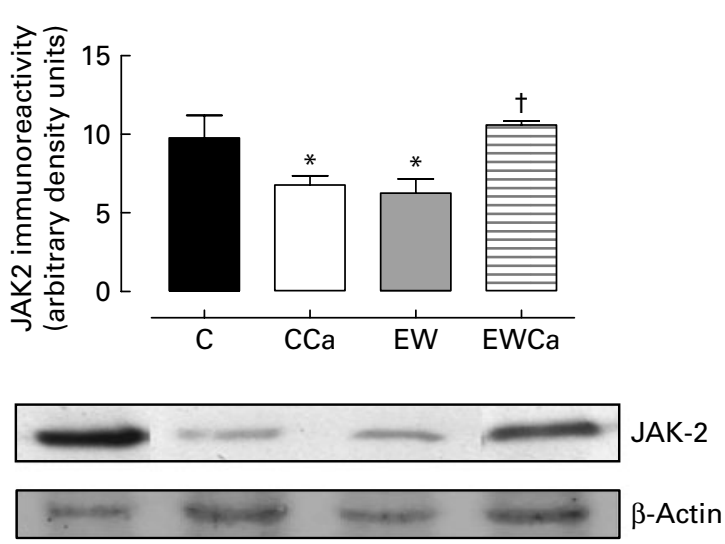

(d)
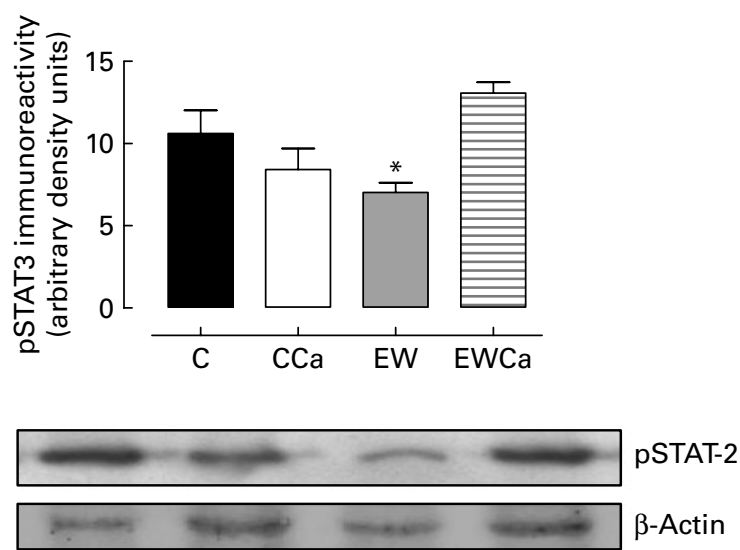

(c)
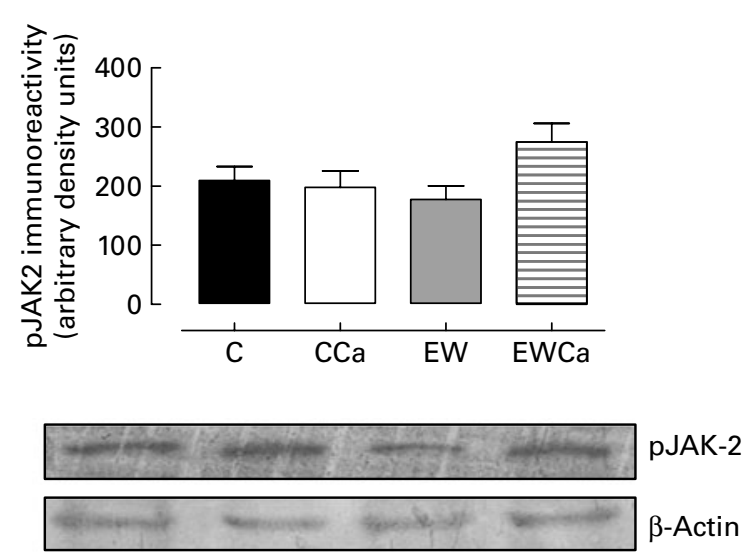

(e)
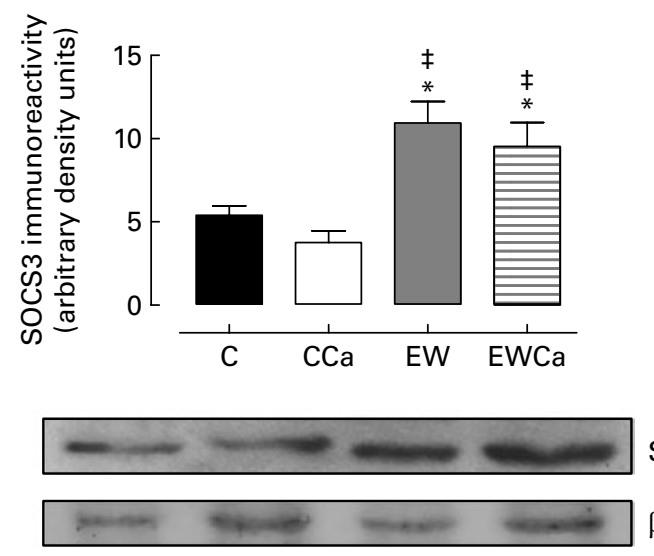

SOCS-3

$\beta$-Actin

Fig. 4. (a) Serum leptin and the effect of dietary calcium (Ca) supplementation for 2 months on protein content of leptin signalling pathway - (b) Janus tyrosine kinase 2 (JAK2), (c) phosphorylated JAK2 (pJAK2), (d) phosphorylated signal transducer and activator of transcription 3 (pSTAT3), (e) suppressor of cytokine signalling 3 (SOCS3) - in the hypothalamus of adult control (C), CCa, early weaning (EW) and EWCa rats. Detections were performed by Western blotting and protein contents were quantified by scanning densitometry of the bands. Actin content was used as control loading. Values are means, with their standard errors represented by vertical bars, $n 10$. * Mean values were significantly different from those of $\mathrm{C}(P<0 \cdot 05)$. †Mean values were significantly different from those of EW $(P<0.05)$. $\ddagger$ Mean values were significantly different from those of CCa $(P<0.05)$. 
(a)

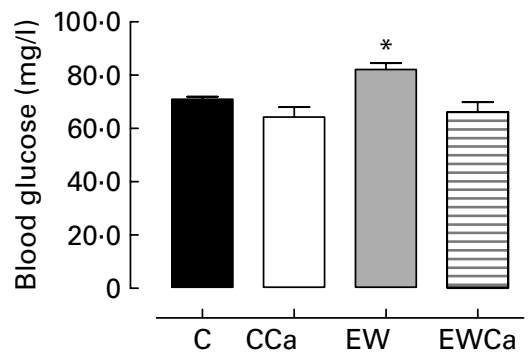

(d)

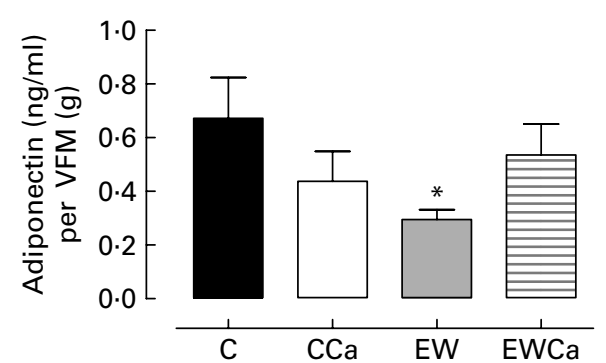

(b)

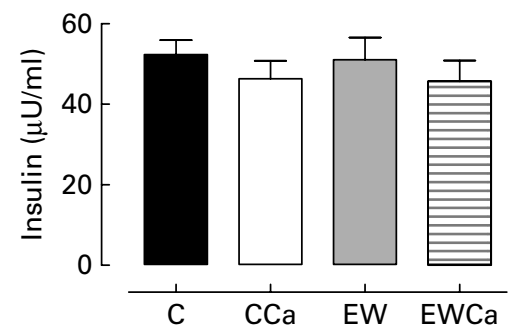

(c)

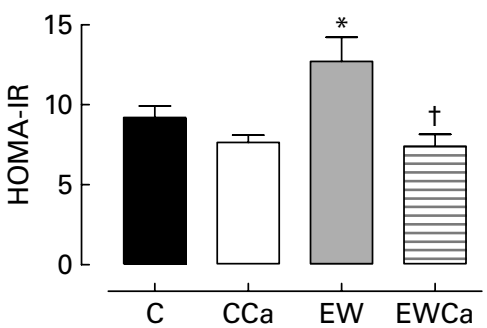

(e)

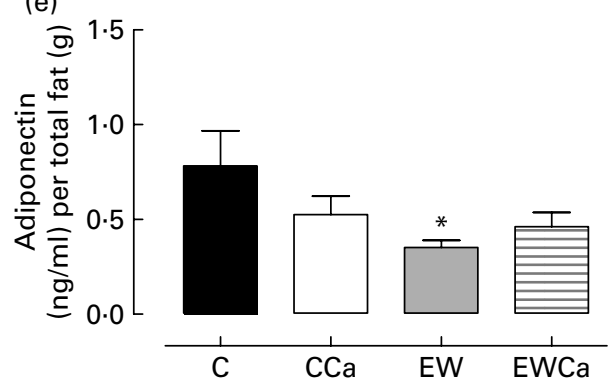

Fig. 5. (a) Glycaemia, (b) insulinaemia, (c) homeostasis model assessment of insulin resistance (HOMA-IR), (d) adiponectin:visceral fat mass (VFM) ratio and (e) adiponectin:total fat ratio of adult control (C) and early weaning (EW) offspring treated with dietary calcium (Ca) supplementation for 2 months (CCa and EWCa). Values are means, with their standard errors represented by vertical bars, $n 10$. ${ }^{*}$ Mean values were significantly different from those of $C(P<0 \cdot 05)$. † Mean value was significantly different from that of $\mathrm{EW}(P<0.05)$

Experimental data were analysed by two-way ANOVA and the Newman-Keuls multiple comparison tests. The significance level was set at $P<0 \cdot 05$.

\section{Results}

Before Ca treatment (at 4 months), C and EW offspring did not present any change in BW or food intake. After 2 months of dietary $\mathrm{Ca}$ treatment, calcaemia and phosphataemia were not significantly different among the groups (Fig. 1(a) and (b)). As expected, the 180-d-old EW offspring (EW nonsupplemented with $\mathrm{Ca}$ ) showed higher BW, hyperphagia and high feed efficiency (9, 28 and 45\%, respectively, $P<0.05$; Fig. $1(\mathrm{a}-\mathrm{c}))$, higher visceral and total body fat content (77 and 55\%, respectively, $P<0.05$; Figs. 2 (a) and (b) and 3) and hyperleptinaemia (twofold increase, $P<0.05$; Fig. 4(a)); however, there was no difference in subcutaneous fat (Fig. 2(c)). These changes were normalised by dietary $\mathrm{Ca}$ supplementation for 2 months. Protein levels of the leptin signalling pathway in the hypothalamus are shown in
Fig. 4. Adult EW offspring showed lower hypothalamic JAK2 ( $-36 \%$, Fig. 4(b); $P<0 \cdot 05$ ), pSTAT3 ( $-34 \%$, Fig. 4(d); $P<0.05$ ) and higher SOCS3 (twofold increase, Fig. 4(e); $P<0.05)$ expressions, and $\mathrm{Ca}$ supplementation normalised JAK2 and pSTAT3. Ca treatment in C offspring caused lower hypothalamic JAK2 content $(-31 \%$, Fig. $4(\mathrm{~b}) ; P<0.05)$. OB-R content was not significantly altered by programming or Ca supplementation (data not shown).

With regard to glucose homeostasis, adult EW rats showed hyperglycaemia $(16 \%, P<0 \cdot 05$; Fig. 5(a)), higher HOMA-IR (38\%, $P<0.05$; Fig. 5(c)), lower adiponectin:VFM ratio and adiponectin:total fat ratio $(-44 \%$, Fig. $5(d)$ and $-45 \%$, Fig. 5(e), respectively, $P<0 \cdot 05)$. These parameters were normalised by dietary $\mathrm{Ca}$ supplementation. Serum insulin (Fig. 5(b)) and adiponectin (C, 7.07 (SEM 0.63); CCa, 7.45 (sem 0.55); EW, 7.45 (sem 0.40); EWCa, 7.43 (sem 0.50)) levels were not changed with or without Ca therapy.

With regard to lipid profile (Table 1), EW offspring presented hypertriacylglycerolaemia $(64 \%, P<0 \cdot 05)$. EWCa offspring showed higher serum HDL-cholesterol $(11 \%, P<0.05)$

Table 1. Lipid profile of adult control (C) and early weaning (EW) offspring treated with dietary calcium (Ca) supplementation for 2 months (CCa and EWCa)

(Mean values with their standard errors, $n 10$ )

\begin{tabular}{|c|c|c|c|c|c|c|c|c|}
\hline & \multicolumn{2}{|c|}{ C } & \multicolumn{2}{|c|}{$\mathrm{CCa}$} & \multicolumn{2}{|c|}{ EW } & \multicolumn{2}{|c|}{ EWCa } \\
\hline & Mean & SEM & Mean & SEM & Mean & SEM & Mean & SEM \\
\hline Total cholesterol (mg/l) & 591 & 34 & 757 & 95 & 767 & 30.9 & 815 & 85 \\
\hline HDL-cholesterol (mg/l) & 259 & 6 & 283 & 21 & 234 & $11 \cdot 3$ & $287^{\star}$ & 9 \\
\hline LDL-cholesterol (mg/l) & 196 & 35 & 192 & 43 & 232 & $35 \cdot 8$ & 270 & 86 \\
\hline VLDL-cholesterol (mg/l) & 243 & 29 & 356 & 59 & 307 & $40 \cdot 3$ & 275 & 41 \\
\hline TAG $(\mathrm{mg} / \mathrm{l})$ & 1143 & $138 \cdot 3$ & 1390 & $215 \cdot 6$ & $1878 \dagger$ & 249 & 1375 & 201 \\
\hline
\end{tabular}

* Mean values were significantly different from those of EW.

$\dagger$ Mean values were significantly different from those of $C(P<0.05)$. 
Table 2. Serum thyroid hormones of adult control (C) and early weaning (EW) offspring treated with dietary calcium ( $\mathrm{Ca}$ ) supplementation for 2 months (CCa and EWCa)

(Mean values with their standard errors, $n$ 10)

\begin{tabular}{|c|c|c|c|c|c|c|c|c|}
\hline & \multicolumn{2}{|c|}{$C$} & \multicolumn{2}{|c|}{$\mathrm{CCa}$} & \multicolumn{2}{|c|}{ EW } & \multicolumn{2}{|c|}{ EWCa } \\
\hline & Mean & SEM & Mean & SEM & Mean & SEM & Mean & SEM \\
\hline Total T3 (ng/l) & 743.6 & 37.4 & 728.6 & 45.9 & 839.2 & 62 & 791.8 & 76.9 \\
\hline Free T3 (pg/l) & $16 \cdot 5$ & 0.9 & $21 \cdot 0$ & 1.4 & $20 \cdot 9$ & 1.8 & $22 \cdot 6$ & 4.0 \\
\hline Total T4 $(\mu \mathrm{g} / \mathrm{l})$ & 33.6 & $2 \cdot 3$ & 41.7 & 3.9 & 39.7 & 1.6 & 47.5 & 3.8 \\
\hline Free T4 (ng/l) & 3.3 & 0.2 & 3.4 & 0.2 & 3.7 & 0.2 & 3.7 & 0.3 \\
\hline
\end{tabular}

T3, triiodothyronine; T4, thyroxine.

and normal serum TAG. Other lipoproteins or total cholesterol were not affected by programming or Ca treatment.

Serum-free or total thyroid hormones levels were not significantly different among the groups (Table 2).

\section{Discussion}

In humans, a significant decrease in abdominal obesity was shown with Ca supplementation or a diet rich in dairy products, and some studies have found that higher Ca intake is inversely associated with the prevalence of the metabolic syndrome ${ }^{(23,35,37,41,43-46)}$. More recently, our group evidenced in an experimental model of early weaning a programming effect for higher visceral, total body fat mass, insulin resistance, hypertriacylglycerolaemia and central leptin resistance in adulthood ${ }^{(21)}$. The present data showed that these disturbances were prevented by $60 \mathrm{~d}$ of dietary Ca supplementation when started in young adult rats $(120 \mathrm{~d}$ old). These rats either presented higher feed efficiency that was normalised with a Ca-rich diet.

Because dairy products have other substances, such as $\mathrm{Mg}$ and leucine, which could affect the interpretation of the present findings, we chose calcium carbonate instead of dairy products. Ca treatment caused no significant increase in serum $\mathrm{Ca}$ and phosphate levels. The absence of substantial changes in calcaemia and phosphataemia after $60 \mathrm{~d}$ of treatment in CCa and EWCa offspring could be expected due to the very tight homeostatic mechanisms for the maintenance of serum $\mathrm{Ca}$, which are mainly performed by parathyroid hormones and calcitriol ${ }^{(47,48)}$. Also, these results point to the fact that the Ca dose used in the present study was not toxic to the animals.

It is well known that leptin levels decrease during weight and fat losses ${ }^{(49,50)}$. In the present study, Ca supplementation was capable of decreasing total and VFM in EW offspring, which reflects in normoleptinaemia.

It is possible that calcitriol can play a role in energy metabolism by regulating the deposition and expansion of local fat in adipose tissue. The higher deposition of central fat in obesity may be due to the greater capacity for regeneration of glucocorticoids in the visceral fat depot ${ }^{(50)}$. In the abdominal adipocyte, the availability of intracellular glucocorticoid is controlled by $11 \beta$-hydroxysteroid dehydrogenase- 1 (11ß-HSD-1) activity, which generates local active cortisol (or corticosterone, in rats) from cortisone. Obese individuals have higher mRNA of this enzyme in both subcutaneous and visceral fat tissues ${ }^{(49)}$. Calcitriol directly regulates the local 11ß-HSD-1 expression and cortisol release, indicating a potential role of calcitriol in visceral adiposity ${ }^{(51,52)}$. In the present study, 25-hydroxyvitamin $\mathrm{D}_{3}$ had a huge increase in the EW group that is normalised by Ca supplementation. Thus, it is possible that $\mathrm{Ca}$-rich diets inhibiting the calcitriol result in the inhibition of $11 \beta$-HSD-1 expression. Further studies are necessary to confirm this hypothesis.

In obesity, hyperleptinaemia does not produce the expected satiety or increase in energetic expenditure because of leptin resistance. This process is caused by the downregulation of hypothalamic leptin receptors ${ }^{(53,54)}$, by the reduced blood-brain barrier transport ${ }^{(54,55)}$ or by the impairment of the intracellular transduction pathway ${ }^{(53,56,57)}$. As EW offspring are hyperphagic and present lower JAK2, lower pSTAT and higher SOCS3 expression, suggesting central leptin resistance $^{(21)}$, we analysed the effect of Ca supplementation on the hypothalamic leptin pathway. As expected, the leptin receptor was not affected by programming and also $\mathrm{Ca}$ supplementation did not alter the OB-R content. Ca supplementation normalised JAK2 and pSTAT3 and increased pJAK2, suggesting the prevention of the central leptin resistance development, although the higher SOCS3 was not prevented by a Ca-rich diet. Thus, both lower body mass and fat corrected the leptinaemia and normalised the hypothalamic leptin signalling. Interestingly, CCa offspring showed lower hypothalamic JAK2 expression but no change in pJAK2. Wang et al. ${ }^{(58)}$, in a whole-cell patch-clamp study of neuropeptide $\mathrm{Y}$ and proopiomelanocortin neurons, showed that leptin differently regulates the high voltage-activated $\mathrm{Ca}$ channels in neuropeptide $\mathrm{Y}$ and proopiomelanocortin neurons, decreasing in neuropeptide $\mathrm{Y}$ and increasing in proopiomelanocortin. It was also suggested that intracellular $\mathrm{Ca}$ could differently regulate leptin action in these two neuronal subpopulations. As in nutritional or hormonal imprinting, the development of these neuronal subpopulations can be affected ${ }^{(58)}$, different responses for $\mathrm{Ca}$ and leptin interplay in the hypothalamic neurons can be obtained. The amount of our data may help to explain the inhibitory appetite effect previously reported by others ${ }^{(37)}$. Hyperglycaemia, higher HOMA-IR, lower adiponectin:VFM and lower adiponectin:total fat ratio, despite normal insulin or adiponectin levels, confirm the insulin resistance previously observed in EW offspring ${ }^{(21)}$. Ca therapy was able to reverse this profile. The mechanism by which $\mathrm{Ca}$ improves insulin sensitivity is still elusive. Epidemiological studies showed a negative association between $\mathrm{Ca}$ intake and glycaemia, 
insulinaemia or insulin resistance ${ }^{(29,59)}$. In rodent and human adipocytes, high concentrations of intracellular $\mathrm{Ca}$ reduce insulin-mediated glucose transport ${ }^{(59-61)}$. Normal concentration of intracellular $\mathrm{Ca}$ is essential for insulin secretion by pancreatic $\beta$-cells as well as for insulin-mediated intracellular processes in tissues such as skeletal muscle and adipose tissue. Calcitriol can increase intracellular $\mathrm{Ca}$ on insulin target tissues, and the higher $\mathrm{Ca}$ intake can block the $\mathrm{Ca}$ influx by the inhibition of calcitriol. Thus, Ca intake results in higher insulin sensitivity, leading to a more efficient glucose uptake ${ }^{(62-65)}$.

Hypertriacylglycerolaemia detected in EW offspring can suggest higher risk for atherogenesis development. Ca supplementation in EW offspring corrected serum TAG and increased HDL-cholesterol, shown to be an adjuvant factor for reducing the risk for CVD. Studies showed the relationship between Ca supplementation and lipid profile improvement, such as hypocholesterolaemia, hypotriacylglycerolaemia, higher HDL-cholesterol $^{(66)}$ and higher serum apo A-I, which is the main protein of HDL-cholesterol ${ }^{(67)}$.

Although a hypometabolic status can be easily associated with a thyroid hypofunction, adult offspring programmed by early weaning did not have changes in serum thyroid hormone concentrations. Besides, dietary Ca supplementation did not change the thyroid function of these adult obese rats. Also, to our knowledge, there are no reports associating $\mathrm{Ca}$ supplementation with thyroid functional changes.

It is important to consider that early weaning can impair the hormonal regulation of $\mathrm{Ca}$ homeostasis, and this explains the different effects of $\mathrm{Ca}$ supplementation between the controls and EW-programmed groups.

In summary, our data reinforce the evidence that early weaning programmes for late development of the metabolic syndrome as well as for central leptin resistance. Maybe, both reduction in fat mass and normalisation of leptin resistance induced by 2 months of Ca-rich diet are mechanisms that lead to increased insulin and leptin action. The most remarkable finding of the present study is that dietary Ca supplementation plays a protective role in reducing the risk of some components of the metabolic syndrome. Thus, Ca supplementation seems to be a strategic approach (therapeuti$\mathrm{cal} /$ nutritional) to the treatment of endocrine-metabolic changes in obesity.

\section{Acknowledgements}

The present study was supported by the 'National Council for Scientific and Technological Development' (Conselho Nacional de Desenvolvimento Científico e Tecnológico CNPq), the "Carlos Chagas Filho Research Foundation of the State of Rio de Janeiro' (Fundação Carlos Chagas Filho de Amparo à Pesquisa do Estado do Rio de Janeiro - FAPERJ), Coordination for the Enhancement of Higher Education Personnel (Coordenação de Aperfeiçoamento de Pessoal de Nível Superior - CAPES). J. L. N., E. O. and N. S. L. were recipients of CAPES fellowships. All the authors are grateful to Monica Moura, Ulisses Risso Siqueira, Carlos Alberto Sampaio Guimarães and Marcos Borges for their technical assistance. E. d. O., P. C. L., E. G. d. M. designed the study and wrote the protocol and manuscript. J. L. N., N. d. S. L., J. G. F. and J. F. N. N. were responsible for the animal programming, biochemical and molecular procedures. All the authors contributed to and approved the final manuscript. The authors declare no conflict of interest.

\section{References}

1. Carnethon MR, Loria CM, Hill JO, et al. (2004) Coronary Artery Risk Development in Young Adults study. Risk factors for the metabolic syndrome: the Coronary Artery Risk Development in Young Adults (CARDIA) study, 1985-2001. Diabetes Care 27, 2707-2715.

2. WHO (2011) Obesity and Overweight. Geneva: World Health Organization. http://www.who.int/mediacentre/factsheets/ fs311/en/index.html

3. Arenz S, Rückerl R, Koletzko B, et al. (2004) Breast-feeding and childhood obesity - a systematic review. Int $J$ Obes Relat Metab Disord 28, 1247-1256.

4. Owen CG, Martin RM, Whincup PH, et al. (2006) Does breastfeeding influence risk of type 2 diabetes in later life? A quantitative analysis of published evidence. Am J Clin Nutr 84, 1043-1054

5. Harder T, Bergmann R, Kallischnigg G, et al. (2005) Duration of breastfeeding and risk of overweight: a meta-analysis. Am J Epidemiol 162, 397-403.

6. WHO (2009) Breastfeeding: A Vital Emergency Response. Are you ready? Geneva: World Health Organization.

7. WHO (2003) Global Strategy for Infant and Young Child Feeding. Geneva: World Health Organization.

8. Araújo ED, Gonçalves AK, Cornetta Mda C, et al. (2005) Evaluation of the secretory immunoglobulin A levels in the colostrum and milk of mothers of term and pre-term newborns. Braz J Infect Dis 9, 357-362.

9. Candeias NM (1983) Health education in the prevention of the risk of premature weaning. Rev Saude Publica 17, $71-82$.

10. Godfrey KM \& Barker DJ (2000) Fetal nutrition and adult disease. Am J Clin Nutr 71, 1344S-1352S.

11. Breier BH, Vickers MH, Ikenasio BA, et al. (2001) Fetal programming of appetite and obesity. Mol Cell Endocrinol 185, 73-79.

12. de Moura EG, Lisboa PC \& Passos MC (2008) Neonatal programming of neuroimmunomodulation - role of adipocytokines and neuropeptides. Neuroimmunomodulation 15, 176-188.

13. Vicente LL, de Moura EG, Lisboa PC, et al. (2004) Malnutrition during lactation in rats is associated with higher expression of leptin receptor in the pituitary of adult offspring. Nutrition 20, 924-928.

14. de Moura EG, Lisboa PC, Custodio CM, et al. (2007) Malnutrition during lactation changes growth hormone mRNA expression in offspring at weaning and in adulthood. J Nutr Biochem 18, 134-139.

15. Fagundes AT, Moura EG, Passos MC, et al. (2007) Maternal low-protein diet during lactation programmes body composition and glucose homeostasis in the adult rat offspring. $\mathrm{BrJ}$ Nutr 98, 922-928.

16. Lisboa PC, Fagundes ATS, Denolato ATA, et al. (2008) Neonatal low-protein diet changes deiodinase activities and pituitary TSH response to TRH in adult rats. Exp Biol Med (Maywood) 233, 57-63.

17. Fagundes AT, Moura EG, Passos MC, et al. (2009) Temporal evaluation of body composition, glucose homeostasis and 
lipid profile of male rats programmed by maternal protein restriction during lactation. Horm Metab Res 41, 866-873.

18. Bonomo IT, Lisboa PC, Pereira AR, et al. (2007) Prolactin inhibition in dams during lactation programs for overweight and leptin resistance in adult offspring. J Endocrinol 192, $339-344$.

19. Moura EG, Bonomo IT, Nogueira-Neto JF, et al. (2009) Maternal prolactin inhibition during lactation programs for metabolic syndrome in adult progeny. $J$ Physiol 15, 4919-4929.

20. Bonomo IT, Lisboa PC, Passos MC, et al. (2008) Prolactin inhibition at the end of lactation programs for a central hypothyroidism in adult rat. J Endocrinol 198, 331-337.

21. Lima NS, de Moura EG, Passos MC, et al. (2011) Early weaning causes undernutrition for a short period and programmes some metabolic syndrome components and leptin resistance in adult rat offspring. Br J Nutr 105, 1405-1413.

22. St-Onge MP (2005) Dietary fats, teas, dairy, and nuts: potential functional foods for weight control? Am J Clin Nutr 81, $7-15$.

23. Gonzalez AJ, White E, Kristal A, et al. (2006) Calcium intake and 10-year weight change in middle-aged adults. J Am Diet Assoc 106, 1066-1073.

24. Zemel MB (2005) The role of dairy foods in weight management. J Am Coll Nutr 24, S537-S546.

25. Parikh SJ \& Yanovski JA (2003) Calcium intake and adiposity. Am J Clin Nutr 77, 281-287.

26. Lin YC, Lyle RM, McCabe LD, et al. (2000) Dairy calcium is related to changes in body composition during a two-year exercise intervention in young women. J Am Coll Nutr 19, $754-760$.

27. Choi HK, Willett WC, Stampfer MJ, et al. (2005) Dairy consumption and risk of type 2 diabetes mellitus in men - a prospective study. Arch Intern Med 165, 997-1003.

28. Ma B, Lawson AB, Liese AD, et al. (2006) Dairy, magnesium, and calcium intake in relation to insulin sensitivity: approaches to modeling a dose-dependent association. $\mathrm{Am}$ J Epidemiol 164, 449-458.

29. Pittas AG, Harris SS, Stark PC, et al. (2007) The effects of calcium and vitamin D supplementation on blood glucose and markers of inflammation in nondiabetic adults. Diabetes Care 30, 980-986.

30. Jacqmain M, Doucet E, Despres JP, et al. (2003) Calcium intake, body composition, and lipoprotein-lipid concentrations in adults. Am J Clin Nutr 77, 1448-1452.

31. Reid IR, Ames R, Mason B, et al. (2010) Effects of calcium supplementation on lipids, blood pressure, and body composition in healthy older men: a randomized controlled trial. Am J Clin Nutr 91, 131-139.

32. Zemel MB (2002) Regulation of adiposity and obesity risk by dietary calcium: mechanisms and implications. J Am Coll Nutr 21, 146S-151S.

33. Xiaoyu Z, Payal B, Melissa O, et al. (2007) $1 \alpha, 25(\mathrm{OH}) 2$-vitamin $\mathrm{D}_{3}$ membrane-initiated calcium signaling modulates exocytosis and cell survival. I Steroid Biochem Mol Biol 103, $457-461$.

34. Teegarden D, White KM, Lyle RM, et al. (2008) Calcium and dairy product modulation of lipid utilization and energy expenditure. Obesity 16, 1566-1572.

35. Zemel MB (2005) The role of dairy foods in weight management. J Am Coll Nutr 24, S537-S546.

36. Tordoff MG \& Rabusa SH (1998) Calcium-deprived rats avoid sweet compounds. Br J Nutr 128, 1232-1238.

37. Major GC, Alarie FP, Doré J, et al. (2009) Calcium plus vitamin D supplementation and fat mass loss in female very low-calcium consumers: potential link with a calciumspecific appetite control. Br J Nutr 101, 659-663.

38. Gilbert JA, Joanisse DR, Chaput JP, et al. (2011) Milk supplementation facilitates appetite control in obese women during weight loss: a randomised, single-blind, placebocontrolled trial. Br J Nutr 105, 133-143.

39. Passos M, Ramos CF \& Moura EG (2000) Short and long term effects of malnutrition in rats during lactation on the body weight of offspring. Nutr Res 20, 1603-1612.

40. Reeves PG (1997) Components of the AIN-93 diets as improvements in the AIN-76A diet. J Nutr 127, 838S-841S.

41. Chen J, Dohi S, Tan Z, et al. (2002) The inhibitory effect of local anesthetics on bradykinin-induced phospholipase D activation in rat pheochromocytoma PC12 cells. Anesth Analg 95, 88-97.

42. de Oliveira E, Moura EG, Santos-Silva AP, et al. (2010) Neonatal nicotine exposure causes insulin and leptin resistance and inhibits hypothalamic leptin signaling in adult rat offspring. J Endocrinol 206, 55-63.

43. Liu S, Song Y, Ford ES, et al. (2005) Dietary calcium, vitamin $\mathrm{D}$, and the prevalence of metabolic syndrome in middleaged and older U.S women. Diabetes Care 28, 2926-2932.

44. Azadbakht L, Mirmiran P, Esmaillzadeh A, et al. (2005) Dairy consumption is inversely associated with the prevalence of the metabolic syndrome in Tehranian adults. Am J Clin Nutr 82, 523-530.

45. Ridker PM, Buring JE, Cook NR, et al. (2003) C-reactive protein, the metabolic syndrome, and risk of incident cardiovascular events. An 8-year follow-up of 14719 initially healthy American women. Circulation 107, 391-397.

46. Potts JT (2005) Parathyroid hormone: past and present. J Endocrinol 187, 311-325.

47. Heaney RP (2006) Vitamin D - the iceberg nutrient. J Musculoskelet Neuronal Interact 6, 334-335.

48. Christensen R, Lorenzen JK, Svith CR, et al. (2009) Effect of calcium from dairy and dietary supplements on faecal fat excretion: a meta-analysis of randomized controlled trials. Obes Rev 10, 475-486.

49. Holm JC, Gamborg M, Kaas-Ibsen K, et al. (2007) Time course and determinants of leptin decline during weight loss in obese boys and girls. Int J Pediatr Obes 2, 2-10.

50. Desbriere R, Vuaroqueaux V, Achard V, et al. (2006) 11betahydroxysteroid dehydrogenase type $1 \mathrm{mRNA}$ is increased in both visceral and subcutaneous adipose tissue of obese patients. Obesity 14, 794-798.

51. Zemel MB (2003) Role of dietary calcium and dairy products in modulating adiposity. Lipids 38, 139-146.

52. Monzillo LU, Hamdy O, Horton ES, et al. (2003) Effect of lifestyle modification on adipokine levels in obese subjects with insulin resistance. Obes Res 11, 1048-1054.

53. Jéquier E (2002) Leptin signaling, adiposity, and energy balance. Ann N Y Acad Sci $\mathbf{9 6 7}$, 379-388.

54. Martin RL, Perez E, He YJ, et al. (2000) Leptin resistance is associated with hypothalamic leptin receptor mRNA and protein down regulation. Metabolism 49, 1479-1484.

55. Burguera B, Couce ME, Curran GL, et al. (2000) Obesity is associated with a decreased leptin transport across the blood-brain barrier in rats. Diabetes 49, 1219-1223.

56. Banks WA (2001) Leptin transport across the blood-brain barrier: implications for the cause and treatment of obesity. Curr Pharm Des 7, 125-133.

57. Bouret SG, Draper SJ \& Simerly RB (2004) Formation of projection pathways from the arcuate nucleus of the hypothalamus to hypothalamic regions implicated in the neural control of feeding behavior in mice. J Neurosci 24 , 2797-2805. 
58. Wang JH, Wang F, Yang MJ, et al. (2008) Leptin regulated calcium channels of neuropeptide $\mathrm{Y}$ and proopiomelanocortin neurons by activation of different signal pathways Neuroscience 156, 89-98.

59. Villegas R, Gao Y, Dai Q, et al. (2009) Dietary calcium and magnesium intakes and the risk of type 2 diabetes: the Shanghai Women's Health Study. Am J Clin Nutr 89, 1059-1067.

60. Draznin B, Sussman KE, Eckel RH, et al. (1988) Possible role of cytosolic free calcium concentrations in mediating insulin resistance of obesity and hyperinsulinemia. J Clin Invest $\mathbf{8 2}$ $1848-1852$.

61. Zemel MB (1998) Nutritional and endocrine modulation of intracellularcalcium: implications in obesity, insulin resistance and hypertension. Mol Cell Biochem 188, 129-136.

62. Tremblay A \& Gilbert JA (2009) Milk products, insulin resistance syndrome and type 2 diabetes. J Am Coll Nutr 28, 91S-102S
63. Begum N, Leitner W, Reusch JE, et al. (1993) Glut-4 phosphorylation and its intrinsic activity - mechanism of $\mathrm{Ca}^{2+}$-induced inhibition of insulin-stimulated glucose transport. J Biol Chem 268, 3352-3356.

64. Zemel MB, Kim JH, Woychik RP, et al. (1995) Agouti regulation of intracellular calcium: role in the insulin resistance of viable yellow mice. Proc Natl Acad Sci U S A 92, 4733-4737.

65. Reusch JEB, Begum N, Sussman KE, et al. (1991) Regulation of GLUT-4 phosphorylation by intracellular calcium in adipocytes. Endocrinology 129, 3269-3273.

66. Major GC, Alarie F, Dore J, et al. (2007) Supplementation with calcium + vitamin D enhances the beneficial effect of weight loss on plasma lipid and lipoprotein concentrations. Am J Clin Nutr 85, 54-59.

67. Groot PH, Grose WF, Dijkhuis-Stoffelsma R, et al. (1980) The effect of oral calcium carbonate administration on serum lipoproteins of children with familial hypercholesterolaemia (type II-A). Eur J Pediatr 135, 81-84. 